Trinity University

Digital Commons @ Trinity

Health Care Administration Faculty Research

Health Care Administration

$2-2015$

\title{
Perioperative Nurses' Attitudes Toward the Electronic Health Record
}

Laura S. Yontz

Jennifer L. Zinn

Edward J. Schumacher

Trinity University, eschumac@trinity.edu

Follow this and additional works at: https://digitalcommons.trinity.edu/hca_faculty

Part of the Medicine and Health Sciences Commons

\section{Repository Citation}

Yontz, L.S., Zinn, J.L., \& Schumacher, E.J. (2015). Perioperative nurses' attitudes toward the electronic health record. Journal of PeriAnesthesia Nursing, 30(1), 23-32. doi: 10.1016/j.jopan.2014.01.007

This Article is brought to you for free and open access by the Health Care Administration at Digital Commons @ Trinity. It has been accepted for inclusion in Health Care Administration Faculty Research by an authorized administrator of Digital Commons @ Trinity. For more information, please contact jcostanz@trinity.edu. 


\title{
Perioperative Nurses' Attitudes Toward the Electronic Health Record
}

\author{
Laura S. Yontz, MSN, RN, MPH, CPAN, Jennifer L. Zinn, MSN, RN, CNS-BC, CNOR, \\ Edward J. Schumacher, PbD
}

\begin{abstract}
Background: The adoption of an electronic bealth record (EHR) is mandated under current health care legislation reform. The EHR provides data that are patient centered and improves patient safety. There are limited data; however, regarding the attitudes of perioperative nurses toward the use of the EHR.

Purpose: The purpose of this project was to identify perioperative nurses' attitudes toward the use of the EHR.

Design: Quantitative descriptive survey was used to determine attitudes toward the electronic bealth record.

Methods: Perioperative nurses in a southeastern bealth system completed an online survey to determine their attitudes toward the EHR in providing patient care.

Findings: Overall, respondents felt the EHR was beneficial, did not add to the workload, improved documentation, and would not eliminate any nursing jobs.

Conclusions: Nursing acceptance and the utilization of the EHR are necessary for the successful integration of an EHR and to support the goal of patient-centered care. Identification of attitudes and potential barriers of perioperative nurses in using the EHR will improve patient safety, communication, reduce costs, and empower those who implement an EHR.
\end{abstract}

Keywords: perioperative, attitudes, electronic health record, electronic medical record, research.

(C) 2015 by American Society of PeriAnesthesia Nurses

\section{HEALTH CARE REFORM IS A TOP PRIORITY} in the United States, and the adoption of a standardized electronic health record (EHR) is a major reform component and cost saving tool. ${ }^{1,2}$

\footnotetext{
Laura S. Yontz, MSN, RN, MPH, CPAN, is an Assistant Director of Nursing for the Post Anesthesia Care Unit, Moses H. Cone Memorial Hospital, Greensboro, NC; Jennifer L. Fencl, DNP, RN, CNS-BC, CNOR, is the Clinical Nurse Specialist for the Operative Service Department, Cone Health, Greensboro, NC; and Edward J. Schumacher, PbD, is a Professor and Chair, Department of Economics and Health Care Administration Trinity University, One Trinity Place, San Antonio, TX 78212. Conflicts of interest: None to report.

Address correspondence to Laura S. Yontz, Moses H. Cone Memorial Hospital, 1200 North Elm Street, Greensboro, NC 27401; e-mail address: laura.yontz@conehealth.com.

(C) 2015 by American Society of PeriAnesthesia Nurses $1089-9472 / \$ 36.00$

bttp://dx.doi.org/10.1016/j.jopan.2014.01.007
}

In 2004, President George Bush said in his State of the Union Address “...by computerizing health records, we can avoid dangerous medical mistakes, reduce costs, and improve care" ${ }^{3}$ President Bush then established the Office of the National Coordinator for Health Information Technology (HIT). This office was charged to develop standards and certification for electronic charting systems. In addition to the president's initiative, the Agency for Healthcare Research and Quality launched its National Resource Center for HIT. And in 2007, the National Health Information Network was formed and funded, providing much momentum and attention on HIT from the federal government. ${ }^{3}$

The agency for Healthcare Research and Quality's HIT initiative is part of the nation's strategy to 
put information technology to work in health care. ${ }^{4}$ By developing secure and private electronic health records for all Americans and making health information available electronically when and where it is needed, HIT can improve the quality of care, even as it makes health care more costeffective. ${ }^{4}$ To achieve these advances in HIT, these agencies have intensely focused their initiatives on three goals

- Improve health care decision making

- Support patient-centered care

- Improve the quality and safety of medication management ${ }^{4}$

This early political momentum has crossed political differences and enjoyed continued support and funding, transforming the paper chart into an electronic health record across our nation in many health care organizations. ${ }^{1}$

The Patient Protection and Affordable Care Act, signed on March 23, 2010, is dedicated to providing affordable and quality health care to all Americans. The law also places additional focus on the growing recognition of health information technology as essential to health care reform. ${ }^{3}$ As a component of this law, 19 billion dollars has been earmarked to aid the adoption of HIT and EHRs. The intent of these incentives is to assist health care providers in purchasing and implementing electronic systems. The act also clearly stipulates penalties for both hospitals and physician providers who fail to adopt an electronic record in a meaningful way. ${ }^{3}$

In this highly technological age, computer skills are no longer a nice addition to one's resume; they are an essential skill set needed to safely and efficiently care for patients. ${ }^{1}$ Computers play an integral part in recording and disseminating information in the $21 \mathrm{st}$ century. Communication and information management are key elements in health care organizations as it relates to the quality of care provided. The quality of care that HIT enables can be directly related to the quality of information available to health care professionals. ${ }^{5}$

Use of the EHR can improve the quality of information available to the medical team caring for a patient in any institution. Electronic health records achieve this by transforming confusing and physically unwieldy masses of data to be instantly available, portable, and searchable. Computeraccessible records have the potential to save the cost-strangled American medical system billions of dollars in waste, repetition, and error. ${ }^{6}$ Electronic systems also safely bridge one of the more perilous chasms in medicine: the transfer of care when patients move from one department to another and when they leave the hospital and potentially seek treatment from another health care providers. ${ }^{6}$

Use of the EHR in the perioperative setting offers tremendous advantages to the perioperative team through the creation of accessibility of all patients' information in one location. Additionally, for many patients, the perioperative arena is the initial entry point into the health care system, either through scheduled or unscheduled surgery. Correct and efficient use of the EHR can improve communication throughout the system and help create a safer and more efficient patient-centered experience.

Additional advantages of EHR use in the perioperative setting include clear communication of information to other departments and effectively capturing workload. ${ }^{1}$ Patient care is enhanced and improved when information can be easily accessed. In addition, there is less repetition of patient information gathered and included in documentation. ${ }^{7}$ These advantages aid in the provision of safe handoffs, leading to safe patient care and improved communication throughout the health care system. These advantages also address the perilous chasm involving the transfer of care that takes place every day as patients move in and out of the operative areas.

\section{Literature Review}

There is an abundance of literature describing nurses' attitudes and barriers in using the EHR in medical and/or surgical and critical care units. The literature reflects that documentation and review of the electronic record provide nursing staff with increased knowledge of the patient's current health status and has demonstrated a positive effect on the nurse's care of the patient. This positive effect on patient care is illustrated with improved patient and family involvement in care, efficiency of care, access to information impacting patient safety, improved communication, and independent decision making by the nurse. ${ }^{8,9}$ Electronic health 
records also allow the clinician to focus on patient care; therefore, less time and energy are spent chasing paper information. ${ }^{1}$ Medical and/or surgical and critical care nurses who use the EHR consistently reported fewer poor patient safety and quality outcomes than in hospitals without an EHR. ${ }^{2}$ Nurses working with electronic records were less likely to report that "things fell through the cracks" with regards to hand-offs of patient care and transferring patients between units. ${ }^{2}$ In addition, nurses felt the use of the electronic record better prepared their patients for discharge. ${ }^{2}$

The literature also describes attitudes and barriers to using EHR for various medical and/or surgical nurses. Current literature reflects that the attitudes of these nurses were generally favorable regardless of the nurse's job, title, and age. An older study concluded nurses' attitudes to computers were more unfavorable than favorable. ${ }^{15}$ The nurses did not feel that their paper work was reduced or any time saved through use of the electronic record. ${ }^{17}$ The nurses in this earlier study expressed frustrations at training and support with clinical instructors. ${ }^{17}$

There have been many changes in information technology as a result of findings from this earlier study. Could these negative attitudes have been related to older technology and no longer be significant? More recently, Timmons ${ }^{19}$ and Darbyshire ${ }^{10}$ studied nurses' attitudes and identified resistance to using an EHR. This resistance was not because of any "technophobia" but rather issues with the systems and processes, such as the system did not take into account the ways nurses practice, difficulties in using the system, and irrelevance to patient care. A summary of some recent studies is included in Table 1.

The issues encountered with EHR use can be categorized as both organizational and behavioral. These issues may be attributed to attitudes toward the use of electronic technology or failure of the implementers to seek input from potential users. $^{8,14,16}$ Three general categories of potential barriers have been identified in the literature around implementation of the electronic record. ${ }^{18}$ These categories include the following: (1) characteristics of the computer itself (mobility, ease of log in, ease of use, cord, and batteries); (2) nursing staff or people variables (demographics, prior computer experience, team player, outlook, and time management skills); and (3) organization (available support, training, and time). Successfully managing barriers can facilitate the transition to using a computerized documentation system. In addition, training, support, and information sharing can be critical to successful implementation. ${ }^{18}$

With all the literature exploring the experience of medical and/or surgical nurses and critical care nurses in their use of the EHR, a gap in knowledge related to perioperative nurses was identified. Although advantages of EHR use in perioperative settings include organized information in tabs, easy accessibility, provision of optimal care, and decreased costs ${ }^{1}$; specific attitudes of perioperative staff have not been explored. Saletnik ${ }^{8}$ identifies the commitment of human resources and the necessity of having input from staff using the system but does not discuss attitudes of perioperative staff toward EHR use.

There is limited research evaluating the attitudes of perioperative nurses toward the EHR. Perioperative nurses work in a restricted environment, behind closed doors, and in an isolated and restricted area. ${ }^{18}$ These nurses work with one patient at a time in an intense, stressful, and highly technical environment. Frequently, there is a shortage of experienced personnel. Because the work environment and the nursing skill set required are different, is it possible the attitudes and perceived barriers to using the EHR could be different as well?

\section{Purpose}

The purpose of this project was to assess the attitudes of perioperative nurses toward EHR use in an effort to document patient care and identify any potential perceived barriers to implementation of a new electronic health record for the health system. Nurses surveyed in this project were currently using an EMR to document care and would convert to the new EHR in the summer and fall of 2012. A project questionnaire was distributed.

\section{Project Questions}

- What are the attitudes of perioperative nurses to using the EHR? 
Table 1. Literature Review of Recent Studies

\begin{tabular}{|c|c|c|c|}
\hline Author & Study Group/Subjects & Summary of the Results & $\begin{array}{l}\text { Summary of Identified } \\
\text { Opportunities }\end{array}$ \\
\hline Darbyshire $^{10}$ & $\begin{array}{l}\text { A total of } 13 \text { focus groups with } 53 \\
\text { practitioners across Australia } \\
\text { with medical and/or surgical } \\
\text { nurses and midwives, child } \\
\text { health and/or mental health, } \\
\text { clinical support, emergency, } \\
\text { intensive care, anesthesia and/ } \\
\text { or community health }\end{array}$ & $\begin{array}{l}\text { - Computerization has neither } \\
\text { enhanced their practice nor } \\
\text { their care, nor had it improved } \\
\text { outcomes } \\
\text { - Reduction of administrative } \\
\text { tasks } \\
\text { - Improving legibility } \\
\text { - More time at the bedside } \\
\text { - Replaced paperwork }\end{array}$ & $\begin{array}{l}\text { - Perceived inability to capture } \\
\text { "real nursing" } \\
\text { - Difficulty in use } \\
\text { - Nonresponsiveness } \\
\text { - Irrelevance to patient care- } \\
\text { management tool not patient } \\
\text { care tool } \\
\text { - Incapable of capturing nursing } \\
\text { care }\end{array}$ \\
\hline Dillon $^{11}$ & $\begin{array}{l}\text { All full and part time nurses in a } \\
450 \text { bed regional hospital } \\
\text { center }\end{array}$ & $\begin{array}{l}\text { - Somewhat positive overall } \\
\text { attitude } \\
\text { - Age, a significant factor in } \\
\text { acceptance } \\
\text { - Training and practice technol- } \\
\text { ogy improves attitudes }\end{array}$ & $\begin{array}{l}\text { - Concerns for quality health } \\
\text { care delivery } \\
\text { - Concern about the effects of } \\
\text { the system on staff } \\
\text { - Additional personal effort, } \\
\text { annoying, and maddening }\end{array}$ \\
\hline Huryk $^{12}$ & $\begin{array}{l}\text { Literature review-13 separate } \\
\text { articles }\end{array}$ & $\begin{array}{l}\text { - Overall attitudes positive } \\
\text { - Computer experience indica- } \\
\text { tor for positive attitudes } \\
\text { - Perception of enhanced patient } \\
\text { care and/or safety } \\
\text { - Easy to use system and/or inte- } \\
\text { grated well }\end{array}$ & $\begin{array}{l}\text { - Poor system design, system } \\
\text { slowdown, and downtime } \\
\text { - Fearful that technology will } \\
\text { dehumanize patient care }\end{array}$ \\
\hline Kaya $^{13}$ & $\begin{array}{l}\text { A total of } 890 \text { nurses at one state } \\
\text { and one university hospital in } \\
\text { Turkey }\end{array}$ & $\begin{array}{l}\text { - Nurses in general had positive } \\
\text { attitudes toward computers } \\
\text { - Positive effect of experience } \\
\text { with computers on attitudes to- } \\
\text { ward computers in health care } \\
\text { - Comfortable using user-friendly } \\
\text { computer applications } \\
\text { - Aware of the usefulness of com- } \\
\text { puters in a variety of settings } \\
\text { - Realistic view of current capa- } \\
\text { bilities in health care }\end{array}$ & $\begin{array}{l}\text { - Single nurses more positive } \\
\text { than married; negative effect of } \\
\text { age on attitudes toward com- } \\
\text { puters. } \\
\text { - Should be continuous organi- } \\
\text { zational work in place to } \\
\text { improve attitudes } \\
\text { - Concern that computers were a } \\
\text { threat to their job security }\end{array}$ \\
\hline Moody $^{14}$ & $\begin{array}{l}\text { A total of } 100 \text { nursing personnel } \\
\text { in magnet hospital in Florida }\end{array}$ & $\begin{array}{l}\text { - EHR resulted in decreased } \\
\text { workload } \\
\text { - EHR improved quality of docu- } \\
\text { mentation } \\
\text { - Would lead to improved safety } \\
\text { and patient care } \\
\text { - Nurses with experience with } \\
\text { computers with more favorable } \\
\text { attitudes }\end{array}$ & $\begin{array}{l}\text { - Environment may prevent EHR } \\
\text { documentation at bedside } \\
\text { - Older nurses less positive }\end{array}$ \\
\hline Sultana $^{15}$ & $\begin{array}{l}\text { District general hospital in United } \\
\text { Kingdom, } 58 \text { nurses }\end{array}$ & $\begin{array}{l}\text { - No violation of patient privacy } \\
\text { - Not facing more lawsuits }\end{array}$ & $\begin{array}{l}\text { - Nurses attitudes were generally } \\
\text { more unfavorable } \\
\text { - No reduction in workload } \\
\text { - Efficiency in not increased and/ } \\
\text { or time not saved }\end{array}$ \\
\hline
\end{tabular}


Table 1. Continued

\begin{tabular}{|c|c|c|c|}
\hline Author & Study Group/Subjects & Summary of the Results & $\begin{array}{c}\text { Summary of Identified } \\
\text { Opportunities }\end{array}$ \\
\hline Whitaker $^{16}$ & $\begin{array}{l}\text { A total of } 11 \text { nurses from } \\
\text { oncology and medical and/or } \\
\text { surgical units }\end{array}$ & $\begin{array}{l}\text { - Prior computer experience } \\
\text { useful } \\
\text { - Teamwork and information } \\
\text { sharing essential } \\
\text { - Acceptance and use of HER } \\
\text { enhance when barriers are } \\
\text { identified, managed, and facili- } \\
\text { tators are supported } \\
\text { - Laptops can be taken to } \\
\text { bedside } \\
\text { - Reduces written } \\
\text { documentation }\end{array}$ & $\begin{array}{l}\text { - Lack of computer experience a } \\
\text { negative } \\
\text { - Lack of perceived support } \\
\text { - Laptops slow; log on and/or off } \\
\text { slow } \\
\text { - Batteries dead, missing cords } \\
\text { and/or misplaced computers } \\
\text { may be an issue } \\
\text { - Difficult to find information }\end{array}$ \\
\hline
\end{tabular}

EHR, electronic health record.

- What is the staff perception of the organizational support for staff members using the EHR?

- Do any characteristics of the computer itself make a difference in providing care?

\section{Methods}

\section{Sample and Setting}

The setting for this project was a not-for-profit, integrated tertiary health network in the southeastern United States. The targeted population for this project consisted of 396 nurses. These nurses came from all areas of operative services to include preadmission testing, same day surgery (ie, short-stay center), operating room, and post anesthesia care. All the nurses were invited to participate in the survey. Inclusion criteria for the sample included the following: must be a perioperative registered nurse, willing to participate in the survey, and employed in the health system between February 23, 2012 and March 23, 2012.

\section{Design}

A quantitative descriptive survey design was used to determine perioperative nurses' attitudes toward the use of the electronic record in providing and documenting patient care in their work environments. This project was successfully presented at the health system nursing research council and received Institutional Review Board (IRB) approval through the health system and the university involved with the project.

A computer-based learning (CBL) module was written and used to describe and invite the 396 targeted perioperative nurses to participate in the project. CBL was a familiar format for educational activities in the health system, so it was a convenient method to reach the staff. If staff chose to participate, an internet link contained in the $\mathrm{CBL}$ directed them to the intranet-based survey. These perioperative staff nurses voluntarily completed an anonymous online survey, responding to questions about their attitudes and use of computers to provide and document safe patient care. Responding to the survey did give staff some credit for participation in a research project on their annual performance appraisal.

\section{Instruments}

A 32-item questionnaire was used to gather demographic data and determine attitudes of the participants. Seven questions gathered demographic information, such as age, race, hospital setting, shift worked, years as nurse and in perioperative services, and education. Fourteen questions sought information about the nurse and could be described as the people variables. Six questions asked about the computer and its characteristics, and four questions asked about the organization 
itself. A four-point Likert scale was used for the people variables, computer variables, and the organization variables. Participants also had the opportunity to write in comments and describe their biggest frustration with using an electronic system and to identify any potential barriers in using the system. Examples of questions on the survey specifically regarding the computer included the following

- I have access to a computer when I need one to document patient care

- All computers on my unit (bedside, portable, and/or desk) have the same functionality

- Use of electronic health records for documentation is more of a help than a hindrance to patient care

- Use of the computer has helped improve documentation of patient care

- Computer documentation of patient care will put some staff out of a job

- There are frequent problems with the computer system in my department at work

The questionnaire used in this study was developed from a survey used in 2004 by Moody et $\mathrm{al}^{14}$ in conjunction with input obtained by two advanced practice nurses working in perioperative services who were also members of the hospital research committee. The survey was modified to better fit the needs of our hospitals' nursing population. Although the survey developed by Moody et $\mathrm{al}^{14}$ had been tested and found to be reliable and valid, we did not specifically test our questionnaire before this project and recognize this as a limitation to the study.

\section{Results}

Eighty nurses, or $20.2 \%$ of the potential subjects, participated in the survey. Most of the respondents were Caucasian ( 72 responses or $91.1 \%$ ), primarily working first shift (60 responses or 76.9\%). Most of the respondents were full time ( 54 responses or $69.2 \%$ ) and between the age of 41 to 60 years of age (58 responses or $73.4 \%$ ). Respondents were from all perioperative areas in the health care system. The highest level of education for 32 of the respondents was an Associate Degree in Nursing; 40 of the respondents' highest degree was a Bachelors of Science in Nursing (BSN). Another 3 respondents had a BS in another field besides nursing, and one respondent had a MS in another non-nursing field.

Nurses responding to the survey were generally favorable to the use of the EHR in documenting patient care (Figure 1). Most of the respondents agreed and/or strongly agreed, they were confident entering patient care information into the computer (70 responses or $89.8 \%$ ), using the EHR will lead to improved patient care (63 responses or $80.8 \%$ ), they had adequate time to document in the record (61 responses or 78.2\%) and using the EHR was beneficial to the nurse (61 responses or $79.2 \%$ ). Nurses felt the computer had helped improve documentation of patient care (68 responses or $87.2 \%$ ), computer documentation did not take them away from their patient (52 responses or $66.6 \%$ ), nor interfered with their ability to care for the patient $(70$ responses or $77.9 \%$ ). Sixty-eight nurses, or $86.1 \%$, used a computer for personal use at home.

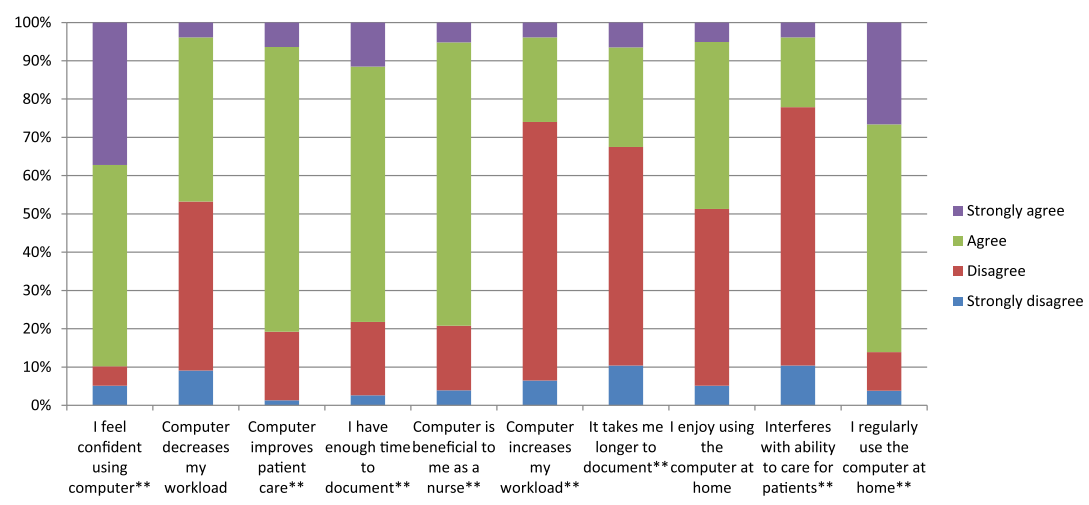

Figure 1. Characteristics of nurses. The ${ }^{* *}$ indicate the proportion of nurses agreeing (agree and strongly agree combined) with the statement is equal to the proportion disagreeing (combining disagree and strongly disagree) at the .01 level of significance. This figure is available in color online at www.jopan.org. 
Nurses were just as likely to agree as disagree that computers decreased their workload, and that they enjoyed using a computer when not at work. In the other cases, however, the proportion who agreed was statistically different from those who disagreed. Nurses were more likely to agree than disagree that they felt confident using the computer, computers improved patient care, they had enough time to document, computers were beneficial to nurses, and they regularly used a computer for personal use at home. The nurses were more likely to disagree than agree that computers increased their workload, that it took longer to document in the computer, and that computer documentation interfered with the ability to care for patients.

Issues related to the computer were also favorable (Figure 2). Respondents felt they had access to a computer when they needed one (66 responses or $83.5 \%$ ), all the computers in their unit had the same functionality ( 55 responses or $70.5 \%$ ), it did not take longer to document care in the computer ( 52 responses or $67.5 \%$ ), and the computer did not create more work for the nurse $(57$ responses or $72.0 \%$ ). In Figure 2, nurses were more likely to agree than disagree that they had access to the computer, that computers had the same functionality, helped more than they hindered, improved documentation, and there were frequent problems with computers. Nurses were more likely to disagree than agree that computers put some staff out of a job and that documentation took staff away from patients.
Frequent problems with the computer were identified by 46 of the respondents. Slowness of the system, slow printers, and system issues were most frequently cited as a frustration. One respondent stated her frustration in "not knowing when the system was down" and the need to "convert to paper charting." Another respondent stated that with computer documentation it was "extremely difficult to get charting done on short cases and the need to 'pre-chart' to have documentation completed at the end of the case." Another respondent liked the automatic recording of vital signs but stated that "the format makes it harder to annotate reasons for outlying vital signs or interventions to manage such."

Nurses' perception of organizational support was generally positive (Figure 3). Nurses felt help was readily available when needed (51 responses or $65.3 \%$ ), and the hospital provided a user-friendly environment with adequate training and backup to support the nurse ( 56 responses or $71.7 \%$ ). Staff comments emphasized the need for adequate support and training. The "lack of support when computer hardware or software malfunctioned" and "not enough practice time before going live" were identified as potential barriers to success. Another staff member felt that there was no back up support for the weekends, especially when the system "froze while on the charting."

Again the proportion who agreed was statistically different from the proportion who disagreed in each case (Figure 3). Nurses were more likely to agree than disagree that help was readily available,

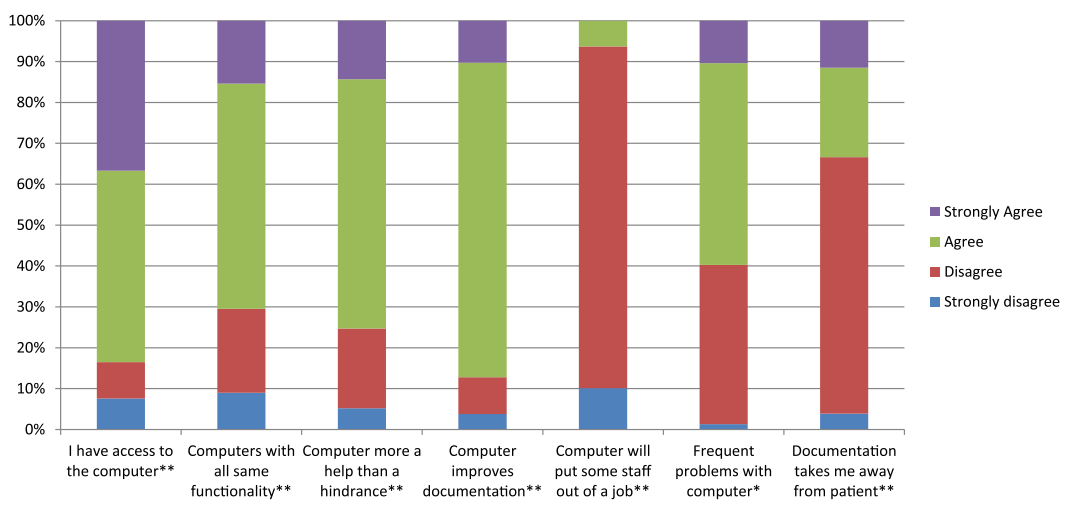

Figure 2. Characteristics of the computer. The ${ }^{* *}$ indicate the proportion of nurses agreeing (agree and strongly agree combined) with the statement is equal to the proportion disagreeing (combining disagree and strongly disagree) at the .01 level of significance, and a single* indicates at the .05 level of significance. This figure is available in color online at www.jopan.org. 


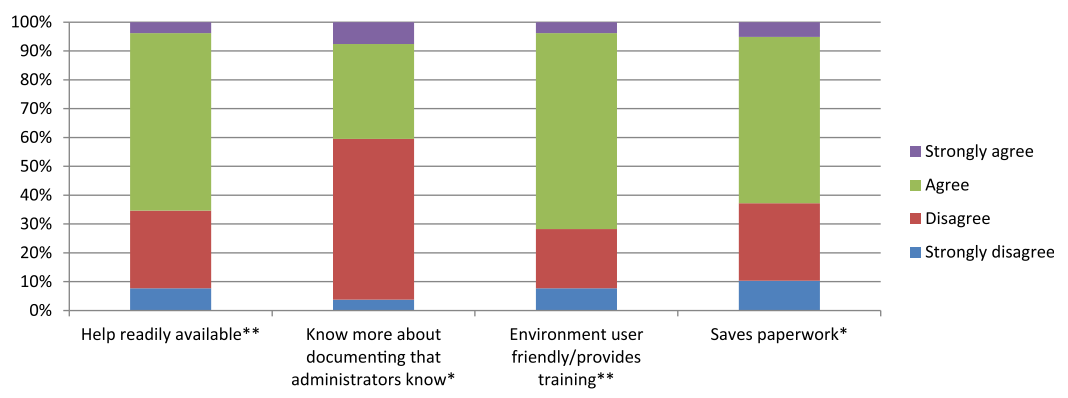

Figure 3. Characteristics of the organization. The ** indicates the proportion of nurses agreeing (agree and strongly agree combined) with the statement is equal to the proportion disagreeing (combining disagree and strongly disagree) at the .01 level of significance. A single * indicates at the .05 level of significance. This figure is available in color online at www.jopan.org.

the hospital provided user-friendly training, and that computers saved paperwork. They were more likely to disagree than agree that they knew more about documenting than administrators knew.

Staff expressed concerns about the location of computer work stations. Comments indicated that they do not like having their back to the patient to document care, nor having the computer across the room from care. Comments included "poor placement (as a potential barrier), nurse has her back to the patient and sterile field" and "It is frustrating to be working with the patient or across the room and need information from the computer." Another respondent felt "... the computer ties the nurse to the wall, and the nurse technician (nursing assistant) felt that we are 'on the computer' and not being helpful or working." One staff member also made a suggestion for hands-free charting.

Overall the biggest source of frustration identified in using an EHR dealt with computer issues: slowness of system (17\% of comments), system freezing (13\% of comments), or not working (11\% of comments). Comments included "slow programs," "I am a little slow," "slow log in," "slow printer," "system freezing up while you are using it," and "not knowing when the system is down." Other frustrations dealt with patient safety issues ( $7 \%$ of comments) including "... tied to wall and cannot be near patient," "length of time charting takes me away from my patient," "(computer) takes me away from patient," and the "focus on charting takes attention away from patient." Documentation issues (7\% of responses) included "having to flip through multiple screens," "not getting done before the surgery is done," having a "proper place to document," "length of time to log-in, to check record \& sign out," "double work" and (we are) "pressed for turnover-the computer needs to be mobile." Other frustrations included charting "not flowing," "too many pages," and "having to call another RN for everything not linked."

Sources of potential barriers to computer documentation included "too many people use same computer," "too few computers, limited workspace," "computers not linked, ... record not well arranged, does not flow in the best order," "program awkward and does not follow work flow," and "who made these (programs)? They obviously do not do this work I am doing". Suggestions were made for bar coding items instead of manual entry of charges and supplies used, and hopes for adequate training for the new system with practice time before going live.

\section{Discussion}

Although an attempt was made to compare the demographics in this project to the national demographics of perioperative nurses to enhance validity of the results, little information was found on demographics for perioperative staff. Study respondents that were slightly older (average age of 48.16), with a higher percentage of nurses in their 40s, but a lower proportion in their $50 \mathrm{~s}$ than demographics from an Association of periOperative Registered Nurses (AORN) survey conducted in 2010. ${ }^{19}$ There was a higher percentage of BSN nurses, no Masters of Science in Nursing (MSN) staff, and less actual experience in perioperative services in this project than in the AORN data. The differences in the results of this project as compared with the AORN survey may be explained by the small sample size. 
In an attempt to compare this project's demographics to the health system, another comparison was made to Magnet demographics that had been collected for the health system (Marjorie Jenkins, $\mathrm{PhD}, \mathrm{RN}$, Magnet Coordinator for Cone Health; e-mail communication, April 2, 2012). These demographics portray the average age of a nurse in operative services was 46.16 years with an average of 25.05 years of nursing experience. The respondents in this project had an average age of 48.16 years, and the average length of service was 19.77 years. Again, this difference could be attributed to the number of small respondents in the project or turnover that has taken place since the Magnet demographics were gathered.

Overall attitudes of the participants responding in this project were positive, similar to results found by Dillon et al, ${ }^{11}$ Kaya, ${ }^{13}$ and Moody et al. ${ }^{14}$ The original intent of this project was to identify perioperative nurses' attitudes toward the EHR. We did make some comparisons with the literature. Nurses stated they were confident in using the computer and regularly use the computer, similar to results found by Moody. ${ }^{14}$ However, Moody ${ }^{14}$ found older nurses held a less positive attitude toward the EHR than their younger peers. Nurses in this project felt that using the computer had improved documentation and would lead to improved patient care. Access to the computer and perceived support from the organization were also positive. There were no significant differences in age, years of experience, or educational level. This aligns with research by Dillon et $\mathrm{al}^{11}$ showing a generally positive attitude across all groupings with the growing acceptance of technology throughout the general population.

Results from this project indicate that the perioperative staff feels that the electronic medical record

- Is beneficial to the nurse

- Does not add to the nurse's workload

- Does not take the nurse away from the patient

- Will not eliminate any nursing positions

Staff written comments in this project expressed dissatisfaction with the current systems that do not communicate with each other, the current need to print records, and the need to document on multiple screens. The biggest source of frustration expressed toward using an EHR was computer malfunction and slowness of the system.
Nurses were in favor of the use of the EHR but were not completely satisfied with the system, similar to results found by Darbyshire ${ }^{10}$ and Huryk. ${ }^{12}$ One written comment in this project stated "they obviously do not do the work I'm doing here," (referring to the writer of the computer program), reflecting the results given by Darbyshire et $\mathrm{al}^{10}$ that irrelevance to patient care and meaningful clinical outcomes is a concern. ${ }^{10}$

\section{Project Limitations}

This survey only included one hospital system in the southeastern United States. Most of the perioperative staff working in this system were currently using an electronic record to document care. This could have attributed to their positive feelings about EHR use because they had successfully implemented one EMR. Attitudes and perceptions may be different in a system that is just beginning to implement a system or one that is not using an electronic system at all.

Data collection took place over a short period of time-30 days. Coincidentally, before this data collection a portion of the new EHR that involved admission, discharge, and/or transfers went live in the health system. Because of this implementation, there was a heightened awareness of using an EHR and the problems with implementation. Implementation of this portion of the EHR could have influenced some survey answers.

Another limitation may have been the type of nurses who elected to participate in the survey. The actual participants may have been a group of nurses who were favorable toward technology and therefore completed the survey. However, if this were a limitation, one might expect to have a higher proportion of younger nurses filling out the survey. Staff participating in the survey received credit on their annual performance review, which may have provided inducement to participate. Additionally, we did not test the questionnaire for reliability and validity because we based it on one that had previously been tested and found to be reliable and valid.

\section{Implications for Nursing}

Nurses constitute the largest group of health care professionals, with experts that serve on 
national committees and participate in initiatives focused on policy, standards, and EHR adoption. Nurses have a profound impact on the quality and cost of health care and are emerging as leaders in the effective use of the EHR to improve safety, quality, and efficiency of health care systems.

Perioperative nurses who participated in this project generally had positive attitudes toward the use of the electronic record. These positive attitudes may empower those who implement an EHR in the perioperative setting. Nurses play a key role during implementation of a new system and staff concerns and frustrations must also be heard and addressed for successful implementation of a new system. ${ }^{8}$ Additional research would be helpful to examine if attitudes of nurses working in the postanesthesia areas would differ from their peers in the operating room.

Nurses are integral in achieving a vision for the nationwide effort to adopt and implement EHR in a meaningful way. ${ }^{3,8}$ The future of nursing depends on a profession willing to be innovative in the use of health information technology and informatics to enhance patient safety, change management, and quality improvement as evidenced by quality outcomes, enhanced workflow, and user acceptance. ${ }^{3}$

\section{References}

1. Roeder J. The electronic medical record in the surgical setting. AORN J. 2009;89:677-686.

2. Kutney-Lee A, Kelly D. The effect of hospital electronic health record adoption on nurse-assessed quality of care and patient safety. J Nurs Adm. 2011;41:466-472.

3. Murphy J. The journey to meaningful use of electronic health records. Nurs Inform. 2010;28:283-286.

4. Agency for Healthcare Research and Qualtiy - Health Information and Technology. US DHHS. Available at: http://healthit. ahrq.gov/portal/server.pt/community/about/562. Accessed April 26, 2012.

5. Oroviogoicoechea C, Watson R, Beortegui E, Remirez S. Nurses' perception of the use of computerized information systems in practice: Questionnaire development. J Clin Nurs. 2010;19:240-248

6. Brown D. VA Takes the Lead in Paperless Care. Washington [DC]: The Washington Post. 2007. April 10, 2007. Available at: http://www.washingtonpost.com/wpdyn/content/article/ 2007/04/06/AR2007040601911_pf.html. Accessed August 29, 2011

7. Noah P. Implementing electronic documentation. Crit Care Nurse. 2011;34:208-212.

8. Saletnik L, Niedlinger M, Wilson M. Nursing resource considerations for implementing an electronic documentation system. AORN J. 2008;87:585-596.

9. Spencer J, Lunsford V. Electronic documentation and the caring nurse-patient relationship. Int J Hum Caring. 2010;14: 30-35.
10. Darbyshire P. 'Rage against the machine? Nurses' and midwives' experience of using computerized patient information systems for clinical information. J Clin Nurs. 2004;13: $17-25$.

11. Dillon T, Blankenship R, Crews T. Nursing attitudes and images of electronic patient record systems. Comput Inform Nurs. 2005;23:139-145.

12. Huryk L. Factors influencing nurses' attitudes towards healthcare information technology. J Nurs Manag. 2010;18: 606-612.

13. Kaya N. Factors affecting nurses' attitudes toward computers in healthcare. Comput Inform Nurs. 2011;29:121-129.

14. Moody L, Slocumb E, Berg B, Jackson D. Electronic health records documentation in nursing: Nurses' perception, attitudes and preferences. Comput Inform Nurs. 2004;22 337-344.

15. Sultana N. Nurses' attitudes towards computerization in clinical practice. J Adv Nurs. 1990;15:696-701.

16. Whitaker A, Aufdenkamp M, Tinley S. Barriers and facilitators to electronic documentation in a rural hospital. $J$ Nurs Scholarsh. 2009;41:293-300.

17. Timmons S. Nurses resisting information technology Nurs Inq. 2003;10:257-269.

18. Bigony L, Lipke T, Lundberg A, McGraw C, Pagac G, Rogers A. Lateral violence in the perioperative setting. AORN J. 2009;89:688-698.

19. Bacon D. Results of the 2010 AORN salary and compensation survey. AORN J. 2010;92:614-630. 